\title{
JURISPRUDENCIA SOBRE EL RECURSO DE PROTECCION EMANADA DE LA ILUSTRISIMA CORTE DE APELACIONES DE LA SERENA
}

\section{Colaboración de su Relator}

Sr. Diego Simpertegui Limare

Esta sección quiere dar a conocer los fallos más interesantes de los Tribunales de Justicia de la cuarta región, en especial los dictados por la I. Corte de Apelaciones de La Serena.

En esta ocasión, centraremos nuestra atención en el Recurso de Protección, tema que es de mucha importancia para la vida jurídica del país.

Sabemos que este recurso (acción), fue creado por el constituyente en 1976 y mantenido en la Constitución Política de la República del año 1980. En efecto, el Artículo 20 de la Ley Fundamental, señala: "El que por causa de actos u omisiones arbitrarios o ilegales sufra privación, perturbación o amenaza en el legítimo ejercicio de los derechos y garantías establecidos en el artículo 19 , números $1^{\circ}, 2^{\circ}, 3^{\circ}$ inciso cuarto, $4^{\circ}, 5^{\circ}$, $6^{\circ}, 9^{\circ}$ inciso final, $11^{\circ}, 12^{\circ}, 13^{\circ}, 15^{\circ}, 16^{\circ}$ en lo relativo a la libertad de trabajo y al derecho a su libre elección y libre contratación, y a lo establecido en el inciso cuarto, 19으, $21^{\circ}, 22^{\circ}, 23^{\circ}, 24^{\circ}$ y $25^{\circ}$ podrá ocurrir por sí o por cualquiera persona a su nombre, a la Corte de Apelaciones respectiva, la que adoptará de inmediato las providencias que juzgue necesarias para restablecer el imperio del derecho y asegurar la debida protección del afectado, sin perjuicio de los demás derechos que pueda hacer valer ante la autoridad o los tribunales correspondientes.

Procederá, también, el recurso de protección en el caso del $N^{\circ} 8$ del artículo 19 , cuando el derecho a vivir en una medio ambiente libre de contaminación sea afectado por un acto arbitrario o ilegal imputable a una autoridad o persona determinada."

Teniendo presente sus características, este recurso tiene por finalidad prestar inmediato amparo al afectado y deja a salvo las acciones y recursos que el ordenamiento jurídico haya previsto para hacer respetar los derechos del agraviado.

Por otra parte, la tramitación ha sido establecida en el Auto Acordado de la Excma. Corte Suprema, de 24 de Junio de 1992.

Hemos seleccionado algunas causas que estimamos de relevancia jurídica y por estimar que sus consideraciones resultan aplicables a diversas situaciones amparadas por similares normas.

I - CAUSA:

"Pedro Farías Soto y Cía. Ltda. contra Sociedad Administradora de Terminales de Buses Ltda." 
Rol- № 96.685 .

Tribunal: I. Corte de Apelaciones de La Serena.

\section{Jurisprudencia:}

No corresponde resolver a través de la vía del recurso de protección la vigencia o término del contrato de arrendamiento ni sobre el cumplimiento o incumplimiento de sus cláusulas, ni respecto de la validez y efectos del desahucio que habría sido dado por la arrendadora.

El dominio puede recaer no sólo sobre objetos materiales, sino también sobre cosas incorporales de tal manera que el recurrente, mientras no se resuelva lo contrario por la autoridad competente, es dueño de su derecho de arrendatario, derecho que ha sido perturbado por la recurrida, al prohibirle el ingreso de sus buses al recinto del Terminal de Buses de La Serena, por un acto privativo de la Administración de dicho local.

La Serena, veinte de Noviembre de mil novecientos ochenta y cinco.

\section{VISTOS:}

A fojas 6 comparece don Pedro Farías Soto, transportista, en representación de la sociedad "Pedro Farías Soto y Cía. Limitada", sociedad comercial, domiciliada para estos efectos en Amunategui esquina El Santo, Local A-13, interponiendo recurso de protección en favor de la mencionada Sociedad, por hechos que estima arbitrarios, ilegales, injustos e ilegítimos, cometidos por la Sociedad Administradora de Terminales de Buses Limitada, la que a partir del primero de Noviembre del año en curso ha negado el ingreso al terminal de buses correspondientes a su Empresa. Manifiesta la recurrente que el $1^{\circ}$ de Noviembre del año 1983 celebró, por la Sociedad que representa, un contrato de arrendamiento con la Sociedad Administradora de Terminales de Buses Ltda., por el local signado como "A13", lo que permite, además, al arrendatario usar de las dependencias del Terminal para que los buses puedan ingresar $y$, entre otras funciones, recoger a sus pasajeros. Este contrato de arrendamiento tiene una cláusula de renovación automática, por lo que llegada cierta época sin que las partes manifiesten su voluntad contraria, se entiende renovado por un año más y así el contrato se renovó del año 1984 al año 1985 y, además, el año 1985 al año 1986, porque la sociedad arrendadora no comunicó a la arrendataria su voluntad de no perseverar en el contrato de arrendamiento. Sin embargo, el 30 de Octubre del año en curso, se le envió una carta a un domicilio que no es el suyo, comunicándole que debe hacer dejación del bien arrendado, el 31 de Octubre del presente año y agregando que los buses de la Empresa no podrán ingresar a contar de la misma fecha. Las medidas de fuerza con que se ha impedido el ingreso de los buses constan del estampado que rola en el Folio 53, Párrafo 8, fecha 1 ㅇ de Noviembre de 1985 y, además, del Acta Notarial de fecha 2 de Noviembre de 1985. Piensa la recurrente que lo anterior constituye un atropello a la Constitución, porque sin que un Tribunal ordinario lo mande, una comisión por su cuenta y riesgo asume las facultades propias de la jurisdicción y determina que la arrendataria no puede usar lo que ha estado usando por dos años. En efecto, la misiva 337 de la arrendadora que amenaza con impedir el ingreso de los buses de la arrendataria, aparece firmada por el Directorio de la Sociedad Administradora de Terminales de Buses Ltda., y cuando el señor Notario levanta el Acta de fecha 2 de Noviembre de 
1985, al preguntarle al empleado del Terminal la razón que existía para impedir el ingreso del Bus de la arrendataria, contestó que por orden de la Administración, los buses de la mencionada Empresa no podían entrar al Terminal. El artículo 19 de la Constitución Política de la República, inciso $4^{2}$ dice que: "Nadie puede ser juzgado por comisiones especiales, sino por el Tribunal que le señale la ley y que se halle establecido por ésta con anterioridad a la iniciación del juicio". Se agrega, en el recurso, que el derecho que tiene la arrendataria para desarrollar sus actividades comerciales se ve entrabado por la acción del Directorio de la Sociedad Administradora de Terminales de Buses Ltda., al no permitir el ingreso de los buses al recinto del Terminal, ya que obliga a los usuarios a desplazarse desde dicho recinto a las afueras del mismo, con el consiguiente perturbador efecto que produce en las personas, lo que perjudica a la arrendataria, ya que el público usuario deja de preferir los servicios que los buses de la arrendataria entregan y el artículo 19 de las constitución Política de la República en su № 21 dice: "El derecho a desarrollar cualquiera actividad económica que no sea contraria a la moral, al orden público o a la seguridad nacional, respetando las normas legales que la regulen". Por último, con la torpe actitud de la Administración, se ha atropellado el derecho de propiedad que la arrendataria tiene sobre su derecho que nace, precisamente, del contrato de arrendamiento, por lo que debe hacerse lugar, en definitiva, al recurso de protección, ordenando que la Sociedad Administradora de Terminales de Buses Ltda. cese en todos sus entorpecimientos a los derechos de la arrendataria y cese en las violaciones al derecho que se han hecho presente en el recurso.

Solicitado informe a la Sociedad Administradora de Terminales de Buses Ltda., de La Serena, éste se agregó a fs. 31 y en él se expresa que es efectivo que celebró un contrato de arrendamiento con el recurrente respecto del Local-Oficina codificado como "A-13" del Edificio Terminal de La Serena; pero es falso que el uso del local permita además al arrendatario usar de las dependencias del Terminal, para los efectos que los Buses puedan ingresar y entre otras funciones recoger a sus pasajeros, como lo sostiene la recurrente y también era falso que el contrato se haya renovado, por cláusula de renovación automática, porque oportunamente se desahució para ponerle término el 31 de Octubre de 1985. Dice que en el caso que es materia de autos, el presunto afectado no ha sufrido privación de un derecho legítimo, desde el momento que pretende incorporar a un contrato extinguido, una situación que ni siquiera estaba contemplada en él, porque el uso de lozas, estacionamientos e ingreso a las dependencias del Terminal no es materia del arrendamiento y quienes pretendan hacerlo deben cancelar el respectivo arancel, en cada oportunidad, derecho que se agota con el retiro y salida del usuario. Agrega que es falso que se pretenda juzgar al recurrente por comisiones especiales, pues consta de la copia autorizada que acompaña que se está pidiendo la constitución del Tribunal Arbitral establecido en el contrato de arrendamiento. En cuanto a las garantías contempladas en los números 21 y 23 de la Constitución Política, se refiere a eventuales derechos cuya fuente sería el contrato que legalmente terminó el 31 de Octubre de 1985, lo que priva al ex-arrendatario de la posibilidad de invocar tal contrato como fundamento de sus derechos en la actualidad. Sostiene que los actos de su parte no son ilegales y arbitrarios, como exige el artículo 20 de la Constitución Política, ya que es privativo de la Administración del Terminal, autorizar el ingreso a sus instalaciones de conformidad al 
Reglamento Interno y a tales prescripciones se ha ceñido rigurosamente. Precisa finalmente, que el Acta de fs. 1 se refiere a la negativa a levantar la barrera de entrada al Terminal, del Bus de propiedad de la Empresa Pullman Bus, persona jurídica que no es recurrente ni arrendataria.

A fs. 33 vta. se ordenó traer los autos en relación.

\section{CON LO RELACIONADO Y CONSIDERANDO:}

Primero: Que el recurrente de protección ha invocado, entre otras garantías atropelladas por la recurrida, el derecho de propiedad que tiene sobre el contrato de arrendamiento y que garantiza el № 24 del artículo 19 de la Constitución Política de la República, encontrándose entre las que señala el artículo 20 del mismo texto constitucional, como aquéllas susceptibles de ser amparadas mediante el recurso de protección, ocurriendo a la Corte de Apelaciones respectiva, para que adopte las providencias que juzgue necesarias, para restablecer el imperio del derecho.

Segundo: Que en este recurso de protección no ha sido cuestionada la celebración de un contrato de arrendamiento entre la Sociedad Administradora de Terminales de Buses Limitada, representa por don Patricio Stuardo Núñeż y don Pedro Farías Soto y Cia. Ltda., por el cual se dió en arrendamiento el local-oficina codificado como A-13 del Edificio Terminal de La Serena, estando sometido en su funcionamiento a las modalidades, condiciones y exigencias que señala el reglamento de co-propiedad del Edificio y además, al reglamento interno que dicte la Sociedad Administradora. En este Reglamento Interno, que se acompañó por la propia recurrida, se señalan las modalidades para embarcar pasajeros en los Buses, como asimismo para desembarcar y se dice expresamente, según se puede leer a fs. 27 que "La azafata deberá hacer pasar. a los señores pasajeros directamente al interior del Terminal." También en él se reglamenta el uso de las lozas.

Tercero: Que de los términos del contrato y del Reglamento Interno, aparece que el arrendamiento de un local en el Terminal de Buses de La Serena, implica, ente otras cosas, la facultad de que los respecțivos. Buses de la arrendataria entren a las lozas del Terminal y la prueba más concreta de ello es la comunicación del Directorio de la Sociedad Administradora de Terminales de Buses Ltda., que en fotocopia autorizada por Notario, rola a fs. 2, en que se hace saber a Pedro Farías Soto y Cía. Ltda. que se ha puesto término al contrato de arrendamiento, respecto a la oficina A-13 y que, en consecuencia, los buses de su empresa "No" podrán ingresar a partir de la fecha que indican. Vale decir, que la entrada de los buses era una consecuencia del contrato de arrendamiento del local A-13, y que si a partir del primero de Noviembre del año 1985, ellos no podrán ingresar, es porque antes de esa fecha "SI" podían ingresar, desde que si así no hubiera sido, ocioso habría sido notificar a la recurrente de su no ingreso.

Cuarto: Que la conclusión anterior es por lo demás la única que está conforme con la lógica, el buen sentido y el objeto para el cual fue construido el Terminal de Buses de esta ciudad, ya que como su nombre lo indica es, por su naturaleza, un Terminal de Buses y no un Terminal de venta de pasajes, puesto que estos últimos pueden ser vendidos en otros lugares de la ciudad, sin ocasionar problemas a los usuarios, en tanto que es un hecho público y notorio en esta ciudad, que el Terminal de Buses se consțruyó, entre otras razones, para que los Buses llegaran a ese Terminal y no entraran a la ciudad mis- 
ma, por los problemas que por su estacionamiento y desplazamiento ocasionan, debido a su gran dimensión.

Quinto: Que no corresponde en estos autos, atendida su naturaleza y objeto decidir sobre la vigencia o término del contrato de arrendamiento, que en fotocopia rola a fs. 14, ni sobre el cumplimiento o incumplimiento de sus cláusulas, ni sobre la validez y efectos del desahucio que se habría dado por la arrendadora; porque ello es materia de otros procedimientos; pero si, mediante él, se pueden adoptar las providencias necesarias para mantener el statu quo vigente, en el desenvolvimiento de los derechos, impidiendo precisamente las acciones de facto que alteren el 'orden jurídico, como en el caso de autos, en que por decisión unilateral de una de las partes, se ha impedido a la otra ejercer los derechos que le otorga un contrato de arrendamiento y que estaba ejerciendo sin perturbaciones y amenazas hasta el 31 de Octubre del año en curso.

Sexto: Que como lo ha dicho la jurisprudencia, "repugna al ordenamiento jurídico que las partes de un contrato, por muy incumplido que éste haya sido, tomen medidas por su cuenta y al margen de la justicia, para obligar a la otra parte a una determinada conducta, de acuerdo al principio de que nadie puede hacerse justicia por si mismo..." (Gaceta Jurídica № 47, pag. 56).

Séptimo: Que de conformidad con lo dispuesto en el artículo 19 № 24 de la Constitución Política y 583 del Código Civil, el dominio puede recaer no sólo sobre objetos materiales, sino también sobre cosas incorporales, de tal manera que el recurrente, mientras no se resuelva lo contrario por la autoridad competente, es dueño de su derecho de arrendamiento, derecho que ha sido perturbado por la Sociedad Administradora de Terminales de Buses Ltda., al prohibirle el ingreso de sus buses al recinto del Terminal de Buses de La Serena, por un acto privativo de la Administración del Terminal, como lo expresa la recurrida en su informe de fs. 31 , acto que conforme a lo que se viene diciendo carece de razón y, por lo tanto, merece el calificativo de arbitrario, como asimismo, al tratarse de una situación esencialmente fáctica, que altera el orden jurídico hasta ese momento vigentes, debe concluirse que es un acto ilegal y, por consiguiente, procede acoger este recurso.

Octavo: Que la circunstancia hecha presente por la recurrida, de que el acta de fs. 1 se refiera a la negativa a levantar la barrera de entrada al Terminal del Bus de propiedad de la Empresa Pullman Bus, persona jurídica que no es ni recurrente ni arrendataria, en nada obsta a la conclusión a que se ha llegado en los fundamentos precedentes, desde que es un hecho reconocido por la recurrida, que es un acto privativo de la Administración del Terminal, autorizar el ingreso a sus instalaciones de conformidad al Reglamento Interno y porque en la carta que en fotocopia rola a fs. 2 , se le comunica a Pedro Farías Soto y Cía. Ltda. que los buses de su empresa "NO" podrán ingresar a partir de la misma fecha (1ำ de Noviembre de 1985).

Por estos fundamentos y visto, además, lo dispuesto en los artículos 19 № 24 y 20 de la Constitución Política de la República de Chile y Auto Acordado de la Excma. Corte Suprema de 29 de Marzo del año 1977 sobre tramitación del recurso de protección de garantías constitucionales, se declara que se acoge el recurso de protección interpuesto a fs. 6 y, por consiguiente, que la Sociedad Administradora de Terminales de Buses Ltda., representada por su Gerente don Patricio Stuardo Núñez, deberá abstenerse de perturbar y amenazar el derecho de dominio de la recurrente sobre el bien incorporal suyo consistente en su derecho de arrendataria y, en especial ,deberá permitir el ac- 
ceso al Terminal de Buses de La Serena, de los pertenecientes a la Empresa Pedro Farías Soto y Cía. Ltda. individualizados comercialmente como Empresa Pullman Bus, sin perjuicio de lo que más adelante puedan acordar las partes contratantes o resolverse por los Tribunales competentes, acerca de la cuestión referida en el presente recurso, todo ello bajo los apercibimientos señalados en el Auto Acordado de la Excma. Corte Suprema, a que se ha hecho referencia.

Comuníquese, regístrese y archívese en su oportunidad.

Redacción del señor Ministro Titular don Hernán Silva Corvalán. Rol N:96.685.

Concurrieron al acuerdo los Ministros titulares Sres. José Pavisic. Orlando Rivera, Hernán Silva y el Ministro Suplente Sr. Gastón Navarrete.

Esta sentencia fue confirmada por la Exçma. Corte Suprema con los votos de los Ministros Titulares Sres. Correa, Ulloa, Zuñiga, Letelier y Jordán.

\section{CONCLUSION:}

En este fallo, la I. Corte de Apelaciones de La Serena, reconoce la eficacia del recurso de protección como instrumento de salvaguarda del statu quo vigente en las relaciones jurídicas preexistentes, capaz en consecuencia de impedir que por vías de hecho, se perturben, menoscaben o amenacen, derechos legalmente constituidos, en virtud de un acuerdo de voluntades, válidamente celebrado.

Se resuelve en esta sentencia que, si bien a través del recurso de protección no puede exigirse un pronunciamiento sobre el fondo de las relaciones contractuales en controversia -por existir vías legales previstas para el efecto- sí se puede por su intermedio corregir y poner pronto remedio a las conductas de facto que alteran el orden jurídico pre-establecido.

II - Causa: " Jeraldo Tapia , Nancy contra Compañía de Cervecerías Unidas ".

Rol No. 17.399

Tribunal : I. Corte de Apelaciones de la Serena .

Jurisprudencia: Que si bien es cierto que el rebalse de las piletas y cámaras del alcantarillado se produjo con el exceso de orujo de cebada y que ésta no es contaminante, ello fue la causa de que también rebalsaran del sistema de alcantarillado las aguas servidas, las que como es de conocimiento público son contaminantes a la salud pública, estimándose que con el mismo hecho se ha visto quebrantado el derecho a vivir en un ambiente libre de contaminación.

La Serena, veintiséis de Mayo de mil novecientos noventa y tres.

\section{VISTOS:}

A fojas 12, doña Nancy Jeraldo Tapia, interpone recurso de protección en contra de la empresa Cervecerías Unidas S.A., representada por don Horacio Rosas Ramírez, fundado en el hecho de que las cámaras y piletas de alcantarillado de su propiedad, como la cámara de calle Balmaceda frente a su propiedad, el día 10 de Febrero del pre- 
sente año, fueron colmatadas de orujos de cebadas proveniente de la Planta de La Serena de la Empresa en cuestión, que se encuentra ubicada en calle Balmaceda entre las calles Brasil y Colón. La fábrica usa en la fabricación de la cerveza cebada cuyos desechos los arroja al alcantarillado público impidiendo con ello el libre escurrimiento de las aguas servidas y la consiguiente inundación de las propiedades aledañas servida por la red de alcantarillado.

La forma de eliminar los desechos constituye un acto arbitrario e ilegal y atenta contra las garantías constitucionales establecidas en el artículo $19 \mathrm{~N}^{2} 8$ y artículo 20 inciso $2^{\circ}$. de la Constitución Política del Estado que autoriza recurrir de protección en contra de quién, por actos ilegales y arbitrarios, impidan o entraben el derecho constitucional a vivir en un ambiente libre de contaminación, ya que esos desechos contaminan el ambiente y la empresa debe eliminarlo sin causar perjuicios a la población.

Estos hechos han causado perjuicios y daños en su casa habitación ubicada en Balmaceda №269, frente a la Fábrica de la recurrida, la cual quedó inhabilitable por insalubre y debe ser reparada a un costo sobre los $\$ 4.000 .000$.-

Con lo expuesto y prevenido en los artículos № 8 y 24 y el artículo 20 de la Constitución Política del Estado y Auto Acordado de la Excma. Corte Suprema sobre tramitación del recurso de protección, pide se tenga por interpuesto Recurso de Protección en contra de la Empresa Cervecerías Unidas S.A. representada por don Horacio Rosas Ramírez y para proteger su derecho se adopte como medida de protección el prohibirle a la Empresa recurrida de arrojar desperdicios y derechos industriales en el alcantarillado público bajo apercibimiento de proceder al traslado de la fábrica a otro lugar fuera del radio urbano.

A fojas 19 informa el recurrido don Horacio Rosas Ramírez y dice si bien la recurrente interpuso su recurso contra la empresa Cervecerías Unidas S.A. debe entenderse que ello se refiere a la Cía. Cervecerías Unidas S.A, que es el nombre correcto de su representada.

Reconoce que la ubicación y funcionamiento de la Planta tiene más de 40 años y el 4 de Enero de 1984 el Director del Servicio de Salud de Coquimbo dictó resolución autorizando el funcionamiento de la industria de fabricación de bebidas alcohólicas en Balmaceda № 280 de esta ciudad, clasificándola de inofensiva.

Que de acuerdo a la legislación y reglamento vigente, descarga habitualmente al servicio de alcantarillado las aguas servidas y los residuos líquidos, lo que no comprende o incluye al orujo de cebada. Este subproducto, que presta utilidad de forraje a animales, se vende a terceras personas, quienes lo retiran de la Planta mediante camiones. Cuando decae la demanda se regala y a veces tiene que pagar para retirarlo, para ello se hace en la superficie por medio de transporte terrestre.

Pero puede ser el caso que durante el almacenamiento del orujo o durante su retiro en vehículo, alguna pequeña cantidad de esta materia haya caído al piso de la Planta y escurrido a las alcantarillas en la limpieza diaria de los suelos. Esto explica el problema de haberse encontrado orujo de cebada en la red de alcantarillado que va por calle Balmaceda.

Este orujo no puede calificarse de desecho industrial contaminante ya que es producto sólo de la presión o estrujamiento de la cebada sin empleo de agentes químicos. 
La presencia de orujo de cebada en el alcantarillado no indica, precisamente, que éste fue el que produjo la inundación o revenidas de los desagües, ya que ello se pudo deber a defectos propios del sistema de alcantarillado de la propiedad de la recurrente, atendido que se trata de una casa de construcción antigua, de adobes, todo ello unido a que ésta fue la única casa del sector que experimentó este menoscabo y problema.

En cuanto al derecho de propiedad amagado no puede subsanarse con una medida de protección y no es procedente por este medio reparar los daños ocasionados. En cuanto al derecho de vivir en un medio ambiente sin contaminación, la compañía no ha cometido acto arbitrario ya que el orujo de la cebada proveniente de la fabricación de cerveża no contamina. El accidente en la casa de la Sra. Jeraldo se produjo como efecto de la sobre acumulación de aguas sérvidas ordinarias, siendo irrelevante la presencia del orujo de cebada.

Como la compañía no tiene el hábito de arrojar el orujo de cebada al alcantarillado público, la medida de protección es totalmente improcedente y se velará porque el hecho no vuelva a repetirse, ni siquiera accidentalmente.

Termina pidiendo el rechazo del recurso de protección, con expresa condenación en costas.

Se trajeron los autos en relación y en estrado se escuchó el alegato de los abogados de ambas partes.

Como medida para mejor resolver se ofició al Servicio de Salud de la Cuarta región y a la Empresa de Servicios Sanitarios de Coquimbo S.A. para que informen sobre la efectividad de encontrarse colmadas cámaras de desagüe con desechos de la Fábrica del recurrido y sobre la inspección que se hizo a la propiedad de la recurrente, lo que se cumplió a fojas 33 y 39 de autos.

\section{CONSIDERANDO:}

1.- Que Nancy Jeraldo Tapia deduce recurso de protección en contra de la Compañía de Cervecerías Unidas S.A. representada por Horacio Rosas Ramíréz , fundado en que las cámaras y piletas del alcantarillado de su casa se encuentran colmadas de orujo de cebada y desecho de la fabricación de cerveza proveniente de la Planta que tiene al frente de su domicilio en esta ciudad, impidiendo con ello el libre escurrimiento de las aguas servidas y la consiguiente inundación de las propiedades aledañas que son servidas por la red de alcantarillado;

2.- Que esta forma de eliminar estos desechos constituyen un acto arbitrario e ilegal y atentan contra las garantías constitucionales establecidas en el artículo 19 № 8 encuentra dañada por ello y el de vivir en un ambiente libre de contaminación ya que esos elementos contaminan el ambiente y la empresa debe eliminarlos sin causar perjuicios a la población;

3.- Que la recurrente pide se acoja su recurso de protección en contra de la Compañía de Cervecerías Unidas S.A. y se adoptan las medidas de prohibirle el arrojar desperdicios y desechos industriales en el alcantarillado público bajo apercibimiento del proceder al traslado de la fábrica a un sector fuera del radio urbano;

4.- Que informando la recurrida reconoce el hecho de haberse colmado el alcantarillado público y hacerse encontrado en él, orujo de cebada, como también que, de acuerdo a la legislación y reglamento vigente, la fábrica habitualmente descar- 
ga al servicio de alcantarillado las aguas servidas y los residuos líquidos, lo que no comprende o incluye el orujo de la cebada que se use en la fabricación de la cerveza;

5.- Que el subproducto de su fábrica -el orujo de la cebada - es comercializado como alimento de animales y es sacado en camiones por terceras personas. En caso de no haber venta, pagan para que sea retirado, también en transporte terrestre. Reconoce el informante que durante el almacenamiento o durante el retiro de su vehículo, pueden caer pequeña cantidad de orujo, las cuales se escurran a las alcantarillas cuando se hace la limpieza diaria del suelo;

6.- Que la Compañía no tiene el hábito de arrojar al orujo de la cebada al alcantarillado público y la medida de protección es improcedente y se velará por que el hecho no vuelva a repetirse. Estima su improcedencia, porque el derecho de propiedad amagado no puede subsanarse con una medida de protección y por esto no procede repararse los daños ocasionados; tampoco se amaga el derecho a vivir en ambiente sin contaminación, atendido que el orujo de la cebada proveniente de la fabricación de la cerveza no contamina;

7.- Que es un hecho establecido con los elementos de juicio agregados al proceso, cuyo valor probatorio es apreciado en conciencia, que se colmaron las alcantarillas, piletas y cámaras del alcantarillado público que dañaron la casa de la recurrente en tal magnitud que no se podía íntegramente usarla como casa habitación, lo que, por lo demás, ha reconocido la recurrida;

8.- Que en estas circunstancias debe acogerse el recurso de protección deducido en contra de la Cía. Cervecerías Unidas S.A.; por cuanto ésta reconoce que en forma descuidada o no, colmó con los desechos de su fábrica las cámaras y piletas del alcantarillado público, produciendo con ello un daño a la propiedad de la recurrente, $y$

9.- Que si bien es cierto que el rebalse de las piletas y cámaras del alcantarillado se produjo con el exceso de orujo de cebada y que éste no es contaminante, ello fue la causa de que también rebalsaran del sistema de alcantarillado las aguas servidas, las que como es de conocimiento público, son contaminantes a la salud pública, estimándose que con el mismo hecho se ha visto quebrantado el derecho a vivir en un ambiente libre de contaminación.

Por estas consideraciones y lo previsto en los artículos 19 №s 8 y 24 y 20 de la constitución Política de la República y Auto acordado de la Excma. Corte Suprema de 24 de Junio de 1992 sobre Tramitación del Recurso de Protección de Garantías Constitucionales, se declara:

Que SE ACOGE el recurso de protección de fojas 12 deducido por doña Nancy Jeraldo Tapia en contra de la Cía. Cervecerías Unidas S.A. representada por Horacio Rosas Ramírez y se declara que la recurrida Cía. Cervecerías Unidas S.A. representada por Horacio Rosas Ramírez deberá abstenerse de arrojar a los ductos de alcantarillado público, desechos sólidos que se producen en la fabricación de bebidas alcohólicas y analcohólicas en su establecimiento ubicado en esta ciudad en calle Balmaceda entre calles Brasil y Colón, bajo apercibimiento de aplicarle las medidas legales pertinentes si incurrieren en los mismos hechos en que se funda este recurso.

Se condena en costas al recurrido.

Comuníquese, regístrese y archívese en su oportunidad. 
Redacción del Sr.: Ministro Titular, don Federico Pizarro Contador.

Rol № 17.399.-

Pronunciado por los señores Ministros Titulares don Federico Pizarro Contador y Ministros Suplentes don Alfredo Azancot Vallejo y doña María Angelica Schneider Salas.

Mirna Tapia Guzmán, Secretaria Subrogante

Esta sentencia fue confirmada por la Excma. Corte Suprema con los votos de los Ministros Titulares : Srs. Jordán, Araya, Valenzuela, Correa y del abogado integrante Sr. Castro.

\section{CONCLUSION:}

Invoca la recurrente que las cámaras y piletas de alcantarillado de su propiedad como las de calle Balmaceda frente a su domicilio fueron colmadas de orujos de cebada, provenientes de la Planta de la recurrida, a raíz de una arbitraria e ilegal forma de eliminación de desechos, lo que impide el libre escurrimiento de las aguas servidas, afectando el uso de su propiedad y él ejercicio de su derecho de vivir en un ambiente libre de contaminación.

Esta sentencia estima en conciencia que se encuentra probado el rebalse de las piletas y cámaras de alcantarillado, debe ser atribuido al exceso de orujo de cebada, sustancia que no es contaminante. Declara sin embargo, que ese rebalse fue la causa de que también rebalsaran del sistema de alcantarillado, las aguas servidas, las que sí son contaminantes a la salud pública, estimándose que con este hecho se ha quebrantado el derecho a vivir en un ambiente libre de contaminación.

Por medio de este fallo confirmado por la Excma. Corte Suprema, se consagra para el caso específico el derecho subjetivo y a la vez social, a vivir en un medio libre de toda contaminación, superponiendo esta garantía por sobre el desempeño de cualquier actividad económica. Por una parte se destaca el bien jurídico de la salud pública y con ello la obligación del Estado de asegurar a todo ciudadano el derecho de vivir en un ambiente no contaminado. $Y$ por otra parte, se consagra en este fallo el derecho de todo ciudadano para exigir a particulares e incluso a la autoridad, sea cual fuere la actividad que desempeñen y la órbita de actuación, que se abstengan de ejecutar actividades o faenas que pudieran conculcar el antes referido derecho garantizado constitucionalmente, así como el normal desarrollo de sus esferas de extensión.

Las conclusiones hạn sido preparadas por el abogado sr. DANIEL HURTADO NAVIA, Profesor Auxiliar de Derecho Procesal I, en la Escuela de Derecho de la Universidad Católica del Norte. 